\title{
Synthetic hybrid indicators based on scientific collaboration to quantify and evaluate individual research results
}

\author{
Antonio Perianes-Rodríguez ${ }^{\mathrm{a}, \mathrm{d}^{*}}$, Zaida Chinchilla-Rodríguez ${ }^{\mathrm{c}, \mathrm{d}}$, Benjamín Vargas-Quesada ${ }^{\mathrm{b}, \mathrm{d}}$, \\ Carlos Olmeda Gómez ${ }^{\mathrm{a}, \mathrm{d}}$, Félix Moya-Anegón ${ }^{\mathrm{c}, \mathrm{d}}$ \\ ${ }^{a}$ Carlos III University of Madrid. Department of Library and Information Science, Getafe (Spain) \\ bUniversity of Granada, Department of Information Science, Granada (Spain) \\ 'Institute of Public Good and Policies, CSIC, Madrid (Spain). \\ ${ }^{d}$ SCImago Research Group. \\ * Corresponding author at: SCImago Research Group, Department of Library and Information \\ Science, Carlos III University of Madrid, C/Madrid 128, 28903 Getafe, Madrid, Spain. E-mail \\ address: antonio.perianes@uc3m.es (A. Perianes-Rodríguez).
}

Abstract: Governmental initiatives around scientific policy have progressively raised collaboration to priority status. In this context, a need has arisen to broaden the traditional approach to the analysis and study of research results by descending to the group or even the individual scale and supplementing the output-, productivity-, visibility- and impact-based focus with new measures that emphasize collaboration from the vantage of structural analysis. To this end, the present paper proposes new hybrid indicators for the analysis and evaluation of individual research results, popularity and prestige, that combine bibliometric and structural aspects. A case study was conducted of the nine most productive departments in Carlos III University of Madrid. The findings showed hybridization to be a tool sensitive to traditional indicators, but also to the new demands of modern science as a self-organized system of interaction among individuals, furnishing information on researchers' environments and the behavior and attitudes adopted within those environments.

Keywords: Scientific collaboration; Bibliometric analysis; Network analysis; Hybrid indicators

\section{Introduction}

In the last few decades, scientific collaboration has been a core area of study for many researchers. Most of the literature has focused on the analysis of international and national output, scientific domains or research institutions, while studies addressing smaller units such as departments or research groups are less common (Bordons, Zulueta, Cabrero, \& Barrigón, 1995; Bordons \& Zulueta, 1997; Molina, Muñoz, \& Losego, 2000; Molina, Muñoz, \& Domenech, 2002; Zulueta, Cabrero, \& Bordons, 1999; Zulueta \& Bordons, 1999).

Science is a collective activity and collaboration, as an intrinsic feature, is more a need than a choice (Beaver \& Rosen, 1978; Beaver \& Rosen, 1979). For this reason, any number of initiatives have been undertaken to encourage, stimulate and enhance collaboration among 
researchers, while many a policy has been adopted to improve the connections between science and technology through intersectoral scientific collaboration (universities, health systems, private enterprise, and so on).

The message conveyed by governments and bodies that finance research is increasingly explicit: collaboration and association are requisite to research investment, the funding that ensures the quality of the work performed and the savings inherent in equipment and competence sharing. Recent examples are to be found in the latest tenders organized on the European (VII Research Framework Programme (European Union, 2006)), national (Spanish Ingenio 2010 Programme (Ministry of Education and Science, 2006)) and regional (Madrid's IV Scientific Research and Technological Innovation Plan (Community of Madrid, 2005)) level, in which collaboration is a conditio sine qua non and research project applications are only accepted if submitted jointly by several research groups from different institutions, regions and/or countries.

Consequently, scientific collaboration, which is apparently organized and controlled by the scientists themselves, is conditioned by science policy initiatives that have progressively made it a priority (Melin \& Persson, 1996).

In this context, a need has arisen to broaden the traditional approach to the analysis and study of research results, descending to the group or even the individual scale and supplementing the output-, productivity-, visibility- and impact based focus with new measures that emphasize collaboration from the vantage of structural analysis (Acedo et al., 2006; Bonaccorsi \& Daraio, 2003; Börner et al., 2005; Calero et al., 2006; Cohen, 1991; Colman, Dhillon, \& Coulthard, 1995; García-Aracil, Gutiérrez Gracia, \& Pérez-Martín, 2006; Genest \& Thibault, 2001; Kretschmer, 1997; Lee, 2003; Moed et al., 1998; Noyons, Moed, \& van Raan, 1999; Qurashi, 1993; Rey-Rocha, Martín-Sempere, \& Garzón-García, 2002; Rey-Rocha, Garzón-García, \& Martín-Sempere, 2006; Seglen \& Aksnes, 2000; van Leeuwen \& Moed, 2005).

\section{Objectives}

As noted above, collaboration is inherent in scientific activity. And yet its quantitative and qualitative assessment is systematically overlooked, particularly in personal evaluations. The literature contains recurrent references to scoring and crediting systems and indeed, a recent review by Gauffriau et al. described all the methods used to calculate such scores and credits (Gauffriau et al., 2007). One characteristic that most of these have in common is the penalization for collaboration in whatever type of national, institutional or individual aggregate.

The emphasis placed on collaboration by funding bodies is, then, paradoxical, given the general disrepute accorded to collaboration by evaluative bibliometry. This raises a number of questions that call for answers: is it possible to estimate the important role of scientific collaboration when evaluating individual researchers' merits? Can network analysis be used to obtain indicators that furnish information on collaboration and its relationship to individual researcher development? 
The present paper explores the co-authorship networks characterizing Carlos III University of Madrid's (UC3M) nine most productive departments, in an attempt to respond to these questions. The objective is to obtain indicators that combine bibliometric and structural analysis from which to estimate the importance of scientific collaboration, not only when applying for research funding, but also for measuring and evaluating individual achievement.

\section{Methods}

Most bibliometric indicators are formulated on the national scale. Data are gathered on system actors, analyses are conducted on national collaboration, or the numbers of citations obtained by the articles published in a country, region or subject area are tallied. Analyses involving indicators that examine national science systems with data disaggregated by centre or even department are less frequent but nonetheless necessary, for such analyses explore the internal dynamics of national systems in detail. Moreover, to achieve the objectives proposed, indicators must be designed to calibrate individuals' degree of collaboration.

In this context, the use of units of measure deriving from structural analysis acquires particular relevance. Nonetheless, despite their long history and internationally accepted use, network theory and analysis constitute an approach seldom used in Information Science theory or methodology (Otte \& Rousseau, 2002). Fortunately, this trend is changing and network theory and its analysis may signify a quantitative and qualitative leap in the representation and analysis of the structure of all manner of scientific domains, be they defined in terms of geography, subject matter or institution (Vargas-Quesada \& Moya-Anegón, 2007).

In this regard, scientific collaboration networks obtained from co-authorship data are particularly useful for analyses such as addressed here. The advantages of this approach are: (i) these networks describe the characteristics of "academic society" and can reveal the structure of scientific knowledge; (ii) they contain all the necessary components to be regarded to be small worlds: the mean inter nodal distance is small, the clustering coefficient is high and the degree distribution of its nodes fits a power-law distribution; (iii) they are constantly expanding due to the addition of new authors to the databases, ensuring the existence of new nodes that explain the dynamic evolution of this type of networks; (iv) the time when nodes and ties are added to the network, a determining factor for managing their dynamics, can be controlled.

Co-authorship networks are ideal for the intents and purposes of this study. Generated from bibliometric information, they are a source of new information in the form of structural indicators. Such structural information is valuable for the analysis of both the network as a whole and of each of its component actors. The following chapters contain a detailed description of the methodology used to formulate such social networks and introduce the hybrid indicators resulting from the combination of bibliometric and structural analysis.

\subsection{Co-authorship as a unit of measurement}

The author of a scientific paper is defined to be the person who creates the information and drafts the written document. Consequently, intellectual creativity and originality are the basis of scientific authorship. A scientific document is said to be co-signed if there is more than one 
author. And it is regarded to be institutionally co-signed when there is more than one author and each is affiliated with a different institution, department or similar.

Despite the limitations of co-authorship-based inventories (Laudel, 2002; Melin \& Persson, 1996; Subramanyam, 1983; Vuckovic-Dekic, 2003), many a study has used this approach to determine the structure of scientific collaboration and individual researcher status or position. Co-authorship entails stronger social links than bonds based on citation inventories, for it implies that authors are contemporaries and acquaintances; their relationships, therefore, fall within the scope of social network analysis (Liu et al., 2005).

Measuring collaboration in terms of co-authorship embodies several advantages: it is invariable and reliable, in as much as other researchers may access the same series of papers, contributing to the reproducibility of results; it is a practical and inexpensive method of quantifying collaboration; and it can accommodate very large samples, providing for more statistically significant results (Katz, 1992; Katz \& Martin, 1997; Miquel et al., 1989; Smith \& Katz, 2000).

\subsection{Data}

A relational database built with records for the period 2000-2004 taken from the Web of Science ( $\mathrm{SCl}$-expanded, $\mathrm{SSCl}$ and $\mathrm{A} \& \mathrm{HCl}$ ), in which at least one author was affiliated with the Carlos III University of Madrid (UC3M), was used for the bibliometric analysis of research development. In the first phase, all the papers containing the word "Spain" in the address field were retrieved. In a second phase, the subset of papers was further reduced to include only those published from 2000 to 2004 and containing the university's (UC3M) or any of its departments' names or any of its mailing addresses. Thomson Reuters (former Institute for Scientific Information) assigns each journal one or several subject categories. Journal Citation Reports (JCR) for both science and social science for the years analyzedwas the reference used to assign each paper a subject (ISI category). Of the 1383 papers retrieved in all, 442 had been cited.

\subsection{Data refinement}

Bibliographic databases generate problems when used for bibliometric purposes, particularly as regards data errors and inconsistencies (Braun et al., 1995). Quality control is an essential and reiteratively cited issue, but no solution has been in press to date. For both database producers and researchers who download data for scientific purposes, the lack of standardization and errors entail a loss of information, calling for the development of nearly always personalized corrective systems to guarantee scientific rigour, which depends heavily upon data quality (Calero et al., 2006; Gálvez \& Moya-Anegón, 2006; Gálvez \& Moya-Anegón, 2007a; Gálvez \& Moya-Anegón, 2007b).

The importance of standardizing institutional data lies in the progressive rise in the number of papers focusing on such domains. The lack of precision in organizations' names in scientific publications may distort the results of bibliometric analyses (spelling variations, typographical errors, incorrect use of upper case, abuse of initials or abbreviations or mistakes in transliteration), particularly in micro-analysis, and their rectification and unification translate 
into very costly manual procedures. The author field raises similar difficulties: homonymy (two authors with the same name) and synonymy (the existence of different variations on an author's name). To obviate these difficulties, we used ad hoc software that avoids homonymy by combining author and institution and synonymy by combining author and paper, while (Gálvez \& Moya-Anegón, 2006; Gálvez \& Moya-Anegón, 2007b) corrected the lack of precision in institutional denominations.

This study analyzes the data for the UC3M's nine most productive departments (with over 60 papers during the period). In the first refinement step, papers were assigned to each department on the grounds of the data included in the address field, eliminating duplication due to variations in names or postal addresses (Fig. 1). The following step consisted simply in obtaining a list of the authors of each departmental set of papers. The result was that not only department professors, but all national or international authors with whom they had shared authorship, were assigned to departmental output. With the final operation, the removal of the variations in authors' names, the number of authors was lowered from 1949 to 1809.

\subsection{Matrix generation}

Calculating co-authorship from the database described gave rise to symmetric matrices. The headings on the rows and columns in each of the departmental matrices analyzed were authors' names, which led to undirected reciprocal concurrence among them. To avoid the imbalances generated by loops, the values of the main diagonals were eliminated.

Absolute co-authorship values were used in all calculations and analyses. In this regard, a number of authors have maintained that measure normalization introduces distortion in data distributions and that raw data are valid and sufficient for conversion to distance (Leydesdorff \& Vaughan, 2006; White, 2003). Table 1 lists the main indicators for the nine networks analyzed.

Fig. 1. Software for refining author affiliation.

\begin{tabular}{|c|c|c|c|c|c|}
\hline $\mathrm{II}^{\circ}$ & rs_address & & A & $\mathrm{H}^{\circ}$ & Suborganización \\
\hline 1 & Artificial Intelligence Grp, Dept Comp Sci, Madrid 28911, Spain & 回 $\square$ & & $\square \underline{217}$ & Eiblioteconomía y Documentación \\
\hline 2 & Av Univ 30, E-28911 Leqanes, Spain & 圆 & & $\square \underline{218}$ & Ciencia e Ingeniería de Materiales e Ingeniería Química \\
\hline 3 & Avda Univ 30, E-28911 Madrid, Spain & 回 $\square$ & & $\square \underline{219}$ & Ciencia Poltica y Sociología \\
\hline 4 & Avda Univ 30, Leganes 28911, Spain & 回 & & $\square \underline{220}$ & Derecho Público del Estado \\
\hline 5 & & & & $\square \underline{221}$ & Derecho Internacional, Eclesiástico y Filosotía del Derecho \\
\hline & Calle Madrid 126, Madrid 28903, Spain & $\square$ & & $\square \underline{222}$ & Derecho Penal, Procesal e Historia del Derecho \\
\hline 6 & Carlos 3 Univ, Mech Engn Dept, Avd Univ 30, Madrid 28911, Spain & $\square$ & & $\square \underline{223}$ & Derecho Privado \\
\hline 7 & Carlos 3 Univ, Mech Enan Dept, Madrid 28911, Spain & $\square$ & & $\square \underline{224}$ & Derecho Social e Internacional Privado \\
\hline 8 & Carlos III Univ Getafe, Social \& Law Sci Sch, Madrid, Spain & 圆 $\square$ & & $\square \underline{225}$ & Economía \\
\hline 9 & Carlos III Univ Leqanes, Comp Secur Grp, Madrid, Spain & 凅 $\square$ & & $\square \underline{226}$ & $\begin{array}{l}\text { Economía de la Empresa } \\
\text { Estadística }\end{array}$ \\
\hline 10 & Carlos III Univ Madrid, Dept Comp Sci, Butarque 15, Madrid 28911, Spain & $\square$ & & $\square \underline{228}$ & Física \\
\hline 11 & Carlos III Univ Madrid, Dept Comp Sci, Madrid 28911, Spain & 區 $\square$ & & $\square \underline{229}$ & Q Historia Económica e Instituciones \\
\hline 12 & $\begin{array}{l}\text { Carlos III Univ Madrid, Dept Continuum Mech \& Struct Anal, Avda Univ } 30 \\
\text { Leganes 28911, Madrid, Spain }\end{array}$ & 凅 $\square$ & & $\square \underline{230}$ & Hurnanidades: Lingüistica, Literatura, Historia y Estética \\
\hline 13 & $\begin{array}{l}\text { Carlos III Univ Madrid, Dept Continuum Mech \& Struct Anal, Leqanes } 28911 \\
\text { Madrid, Spain }\end{array}$ & 且 $\square$ & & & $\begin{array}{l}\text { L Hurnanidades: Filosofía, Lenguas, Teoría de la Literatura y Estudios Clásicos } \\
\text { Hurnanidades: Geografía, Historia Contemporánea y Arte }\end{array}$ \\
\hline 14 & $\begin{array}{l}\text { Carlos III Univ Madrid, Dept Mech Engn, Avda Univ, 30, Leqanes, E-28911 } \\
\text { Madrid, Spain }\end{array}$ & 區 $\square$ & & $\square \underline{233}$ & Informática \\
\hline 15 & Carlos III Univ Madrid, Dept Mech Enqn, E-28911 Madrid, Spain & 區 $\square$ & & $\square \underline{234}$ & $\begin{array}{l}\text { Ingeniería de Sistemas y Automática } \\
\text { Ingeniería Eléctrica }\end{array}$ \\
\hline 16 & Carlos III Univ Madrid, Madrid 28903, Spain & 區 $\square$ & & & \\
\hline 17 & Carlos III Univ, CS Dept, Leqanes, Spain & 凅 $\square$ & $\checkmark$ & Asigna & Eliminar relación \\
\hline
\end{tabular}




\subsection{Popularity and prestige}

A clustering measure must be defined if evidence usable for evaluating authors' scientific collaboration is to be obtained. Watts and Strogatz introduced what they called the clustering coefficient. The following example explains the idea simply: if A cooperates with four authors and they in turn have all worked together, each of them can be connected by a tie, generating a total of six such links. Now assume that one of A's partners does not collaborate with the others. The number of ties in this case will be less than six. Here the clustering coefficient of $A^{\prime}$ s circle of partners is obtained by dividing the actual by the total possible number of ties (Watts \& Strogatz, 1998).

The clustering coefficient, then, indicates the density of the relationships among the partners around a given node. Values close to one denote a high rate of collaboration among the actors. Figures close to zero, by contrast, mean that the node is the sole tie among partners (Barabási, 2002). This indicator has been used, for instance, in studies analyzing research projects awarded by the European Union, albeit as a global structural indicator to estimate the degree of network cohesion rather than to evaluate individual actors (Wagner \& Leydesdorff, 2005). The clustering coefficient is defined as follows (Batagelj \& Mrvar, 2004):

$$
C C(v)=\frac{\left|E\left(G_{1}(v)\right)\right|}{\left|E\left(G_{2}(v)\right)\right|} \quad C C^{\prime}(v)=\frac{\operatorname{deg}(v)}{\operatorname{MaxDeg}} C C(v)
$$

where $\operatorname{deg}(v)$ is the degree of vertex $v,|E(G 1(v))|$ is the number of ties among the vertices in neighborhood 1 around vertex $v$, MaxDeg is the maximum degree attained by any vertex in the network and $|\mathrm{E}(\mathrm{G} 2(\mathrm{v}))|$ is the number of ties or edges among the vertices in neighborhoods 1 and 2 around vertex $v$. If deg $(v)$ is less than or equal to one, all the coefficients for this vertex will be zero.

Degree, in turn, is the simplest and most intuitive way to measure graph centrality, and is defined to be the number of actors to whom an actor is directly linked. This measure of centrality ranks actors by their number of direct relations in the network as a whole (Degenne \& Forsé, 1999; Hanneman \& Riddle, 2005; Herrero, 2000; Mrvar, 2000; Rogers \& Kincaid, 1981).

$$
C_{d}\left(n_{i}\right)=\frac{\mathrm{d}\left(\mathrm{n}_{\mathrm{i}}\right)}{N-1}
$$

where $\mathrm{d}(\mathrm{ni})$ is the actor's degree and $\mathrm{N}$ the total number of nodes in the network.

In real networks, most nodes exhibit attachment preferences. A new website, for instance, will tend to include links to very popular documents or pages. This example illustrates that the probability that a new node will connect to existing nodes is not evenly distributed, but rather that the likelihood of connection to nodes with a larger number of ties is higher, as (degree, closeness and betweenness) centrality measures show. But the existence of cumulative advantage or preferential attachment (Barabási, Albert, \& Jeong, 1999; Price, 1976), characteristic of network theory, is also applicable to bibliometric indicators. 
Table 1. Basic network indexes. 2000-2004.

\begin{tabular}{|l|r|r|r|r|r|r|r|r|r|}
\hline \multicolumn{1}{|c|}{ Indicators } & \multicolumn{1}{|c|}{ COMP } & ECO & \multicolumn{1}{c|}{ BUSI } & \multicolumn{1}{l|}{ STAT } & PHY & MATER & MATH & COMM & ELEC \\
\hline Nodes & 177 & 169 & 64 & 138 & 340 & 184 & 204 & 139 & 151 \\
\hline Density & 0.05 & 0.02 & 0.03 & 0.06 & 0.04 & 0.04 & 0.02 & 0.04 & 0.16 \\
\hline Degree & 0.16 & 0.1 & 0.11 & 0.16 & 0.26 & 0.31 & 0.16 & 0.15 & 0.29 \\
\hline Betweenness & 0.35 & 0.01 & 0.01 & 0.05 & 0.43 & 0.32 & 0.09 & 0.15 & 0.09 \\
\hline Clustering coefficient & 0.13 & 0.1 & 0.12 & 0.23 & 0.05 & 0.03 & 0.03 & 0.07 & 0.3 \\
\hline Components & 4 & 32 & 32 & 12 & 6 & 4 & 13 & 5 & 7 \\
\hline Size principal component (\%) & 93.79 & 15.38 & 15.63 & 29.71 & 93.24 & 74.73 & 31.86 & 64.23 & 52.32 \\
\hline Size second component (\%) & 3.39 & 10.06 & 9.38 & 26.09 & 2.06 & 20.97 & 29.9 & 16.79 & 19.87 \\
\hline
\end{tabular}

COMP: Computer Science, ECO: Economy, BUSI: Business Administration, STAT: Statistics, PHY: Physics, MATER: Materials Science, MATH: Mathematics, COMM: Communication Technologies, ELEC: Electronic Technology.

Indeed, a very prolific professor will tend to draw a larger number of new researchers. In this case, popularity is understood to mean not a preference for nodes with a larger number of ties, but the choice of larger nodes (in co-authorship networks node volume is generally determined on the basis of the number of documents published). Both the centrality indicators used in network analysis and the output indicator deriving from bibliometric analyses are understood to be measures of prominence or popularity.

But such prominence or popularity should be scaled or supplemented by indicators that reflect and distinguish among popular nodes. In this regard, another series of bibliometric indicators plays a decisive role in the evaluation of contributions, based on visibility or utility for the scientific community, rather than quantity. Of the several possibilities, citation tallying, particularly the observed or real and not expected or estimated citations, is the most prominent (Aksnes \& Sivertsen, 2004; Molas-Gallart \& Salter, 2002; Tijssen, Visser, \& van Leeuwen, 2002), once the problems inherent in aggregate citation counts are solved (Olmeda Gómez et al., 2005). The indicators designed to qualify popularity can be understood to be measures of prestige. Several previous papers have also addressed this question from both the bibliometric (combination of production and citation in the H-index, (Hirsch, 2005) and structural perspectives (weighting of the importance of the inter-relationships (citations) between journals or papers, using the impact factor (Thomson Reuters, 2008), the SClmago Journal Rank (SCImago Research Group, 2007), the Eigenfactor (Bergstrom Laboratory, 2008) or journal status (Bollen, Rodríguez, \& van de Sompel, 2006).

Mählck and Persson, in turn, noted that information visualization analysis would benefit if an appropriate combination of bibliometric and structural magnitudes could be found, able to characterize and put into perspective the observations about the actors drawn from the graphs obtained, which would always be supplementary to existing indicators (Mählck \& Persson, 2000). 
To this end, the present paper proposes an innovative combination and synthesis of known structural and bibliometric indicators: node clustering coefficient, output and number of citations referring to such output.

$\mathrm{CC}(\mathrm{v}) \times \mathrm{ndoc}(\mathrm{v}) \quad \mathrm{CC}(\mathrm{v}) \times \mathrm{ncitations}(\mathrm{v})$

Popularity index Prestige index

where $n d o c(v)$ is total node $v$ output in the period and $n$ citations $(v)$ is the total number of citations observed for the same node and period.

The clustering coefficient is what relates the bibliometric popularity (number of papers) and prestige (number of citations) indicators to the author's collaboration practices. A new measure can therefore be obtained with which to distinguish between two authors with the same productivity or number of citations. Authors with more cohesive networks of collaborators are regarded to be more "popular" or "prestigious".

The choice of this indicator affords certain advantages over the typical centrality measures (degree, betweenness and closeness), which determine an actor's prominence with respect to other members of the network, but only in terms of relations with the node analyzed. The clustering coefficient, by contrast, evaluates not only the number of relationships (co-authored papers), but also the degree of inter-relationship among neighboring nodes. Therefore, an actor's prominence is not defined solely by the number of inter-connected authors, but by his/her participation in a "neighborhood" where collaboration is open to everyone, and not only to the actor in question.

In short, the popularity index provides a measure that weights the number of papers (popularity) by the cohesion of each node's collaboration pattern. Analogously, the prestige index would qualify the number of citations (prestige) by the degree of cohesion of each author's collaboration pattern.

Such hybrid indicators embody a new approach to research, placing the necessary weight on the degree of collaboration among researchers, which has been ignored to date, despite its vital importance for science and technology policy managers.

\section{Results}

Taken alone, the prestige and popularity indicators are scantly useful for evaluating something as multidimensional as an individual's research merit. Nonetheless, they do make a valuable contribution when combined with other measures. Tables 2-10 give a number of individual indicators, both structural and bibliometric, for the main authors in each of the departments analyzed to create a context as widely informative as possible. The data include author position, output (ndoc), number of observed citations, normalized impact factor (NIF) for output, nodal degree and betweenness centrality, the clustering coefficient and the new hybrid indicators, popularity and prestige. 
Table 2 . Computer Science (more than 6 documents). 2000-2004.

\begin{tabular}{|c|c|c|c|c|c|c|c|c|c|}
\hline Rank & Position & Ndoc & Citations & NIF & Degree & Betweenness & Cluster Coef & Popularity & Prestige \\
\hline 1 & Associate Professor & 23 & 3 & 0.81 & 0.15 & 0.172 & 0.234 & 5.387 & 0.703 \\
\hline 2 & Full Professor & 19 & 3 & 0.85 & 0.09 & 0.226 & 0.060 & 1.139 & 0.180 \\
\hline 3 & Full Professor & 14 & 1 & 0.93 & 0.11 & 0.075 & 0.365 & 5.110 & 0.365 \\
\hline 4 & Full Professor & 13 & 13 & 0.83 & 0.21 & 0.288 & 0.899 & 11.682 & 11.682 \\
\hline 5 & Associate Professor & 13 & 1 & 0.95 & 0.10 & 0.055 & 0.303 & 3.935 & 0.303 \\
\hline 6 & Full Professor & 12 & 13 & 0.88 & 0.06 & 0.054 & 0.013 & 0.159 & 0.172 \\
\hline 7 & Part-time Professor & 11 & 0 & 0.87 & 0.12 & 0.187 & 0.168 & 1.850 & 0 \\
\hline 8 & Full Professor & 10 & 6 & 0.88 & 0.07 & 0.068 & 0.034 & 0.336 & 0.201 \\
\hline 9 & Associate Professor & 10 & 0 & 0.86 & 0.13 & 0.137 & 0.239 & 2.388 & 0 \\
\hline 10 & Associate Professor & 10 & 0 & 0.97 & 0.07 & 0.088 & 0.098 & 0.979 & 0 \\
\hline 11 & Associate Professor & 8 & 2 & 0.78 & 0.04 & 0.031 & 0.020 & 0.162 & 0.040 \\
\hline 12 & Associate Professor & 7 & 4 & 0.81 & 0.06 & 0.360 & 0.012 & 0.083 & 0.047 \\
\hline
\end{tabular}

\begin{tabular}{l|l|l} 
Highest & $2^{\text {nd }}$ highest & $3^{\text {rd }}$ highest \\
\hline
\end{tabular}

Table 3. Economy (more than 3 documents). 2000-2004.

\begin{tabular}{|c|c|c|c|c|c|c|c|c|c|}
\hline Rank & Position & Ndoc & Citations & NIF & Degree & Betweenness & Cluster Coef & Popularity & Prestige \\
\hline 1 & Full Professor & 9 & 4 & 0.88 & 0.12 & 0.0113 & 0.96 & 8.63 & 3.84 \\
\hline 2 & Full Professor & 8 & 6 & 1.20 & 0.07 & 0.0042 & 0.46 & 4.13 & 2.75 \\
\hline 3 & Full Professor & 8 & 5 & 0.94 & 0.02 & 0.0004 & 0.20 & 1.60 & 1 \\
\hline 4 & Full Professor & 7 & 2 & 0.87 & 0.06 & 0.0030 & 0.50 & 4 & 1 \\
\hline 5 & No UC3M & 6 & 5 & 0.92 & 0.01 & 0 & 0.03 & 0.20 & 0.17 \\
\hline 6 & No UC3M & 6 & 5 & 0.92 & 0.01 & 0 & 0.03 & 0.20 & 0.17 \\
\hline 7 & Full Professor & 4 & 4 & 0.99 & 0.02 & 0.0004 & 0.20 & 1.20 & 0.8 \\
\hline 8 & Associate Professor & 4 & 2 & 0.88 & 0.02 & 0.0020 & 0.07 & 0.27 & 0.13 \\
\hline 9 & Full Professor & 4 & 5 & 0.93 & 0.04 & 0.0012 & 0.20 & 1.40 & 1 \\
\hline
\end{tabular}

Table 4. Business Administration (more than 2 documents). 2000-2004.

\begin{tabular}{|c|c|c|c|c|c|c|c|c|c|}
\hline Rank & Position & Ndoc & Citations & NIF & Degree & Betweenness & Cluster Coef & Popularity & Prestige \\
\hline 1 & Full Professor & 9 & 4 & 0.85 & 0.14 & 0.0143 & 1 & 9 & 4 \\
\hline 2 & Associate Professor & 6 & 4 & 1.10 & 0.06 & 0.0020 & 0.44 & 3.56 & 1.78 \\
\hline 3 & No UC3M & 6 & 3 & 0.82 & 0.06 & 0.0008 & 0.12 & 0.73 & 0.36 \\
\hline 4 & Associate Professor & 5 & 2 & 1.36 & 0.08 & 0.0046 & 0.56 & 2.78 & 1.11 \\
\hline 5 & Associate Professor & 4 & 0 & 0.99 & 0.06 & 0.0018 & 0.44 & 1.78 & 0 \\
\hline 6 & No UC3M & 4 & 0 & 0.91 & 0.03 & 0 & 0.06 & 0.22 & 0 \\
\hline 7 & No UC3M & 4 & 2 & 0.78 & 0.03 & 0 & 0.02 & 0.07 & 0.03 \\
\hline 8 & Associate Professor & 3 & 1 & 1.07 & 0.05 & 0.0015 & 0 & 0 & 0 \\
\hline 9 & Full Professor & 3 & 3 & 1.38 & 0.06 & 0.0020 & 0.44 & 1.33 & 1.33 \\
\hline 10 & No UC3M & 3 & 0 & 1.03 & 0.05 & 0.0003 & 0.22 & 0.67 & 0 \\
\hline & & & Highest & $2^{\text {nd }}$ highest & $3^{\text {rd }}$ highest & & & & \\
\hline
\end{tabular}

For reasons of space, each table shows only a sampling of the main authors in each department, listed by output volume. The scale of greys identifies the most prominent values (the darker the higher) in a selection of the indicators listed. 
Table 5. Statistics (more than 3 documents). 2000-2004.

\begin{tabular}{|c|c|c|c|c|c|c|c|c|c|}
\hline Rank & Position & Ndoc & Citations & NIF & Degree & Betweenness & Cluster Coef & Popularity & Prestige \\
\hline 1 & Full Professor & 20 & 14 & 1.02 & 0.10 & 0.0534 & 0.053 & 1.12 & 0.75 \\
\hline 2 & Part-time Professor & 9 & 3 & 1.09 & 0.08 & 0.0042 & 0.367 & 3.3 & 1.1 \\
\hline 3 & Associate Professor & 9 & 5 & 0.85 & 0.02 & 0.0001 & 0.067 & 0.73 & 0.33 \\
\hline 4 & No UC3M & 8 & 1 & 0.93 & 0.03 & 0.0104 & 0.038 & 0.38 & 0.04 \\
\hline 5 & Full Professor & 8 & 8 & 0.88 & 0.04 & 0.0196 & 0.021 & 0.17 & 0.17 \\
\hline 6 & Full Professor & 7 & 5 & 1.31 & 0.04 & 0.0277 & 0.006 & 0.04 & 0.03 \\
\hline 7 & Associate Professor & 7 & 16 & 0.99 & 0.07 & 0.0056 & 0.171 & 2.06 & 2.74 \\
\hline 8 & Associate Professor & 6 & 3 & 0.83 & 0.04 & 0.0026 & 0.067 & 0.47 & 0.2 \\
\hline 9 & Associate Professor & 6 & 7 & 0.85 & 0.03 & 0.0072 & 0.022 & 0.13 & 0.16 \\
\hline 10 & Visiting Professor & 5 & 2 & 0.93 & 0.03 & 0.0082 & 0.027 & 0.16 & 0.05 \\
\hline 11 & Researcher & 5 & 0 & 1.16 & 0.04 & 0.0002 & 0.056 & 0.28 & 0 \\
\hline 12 & Associate Professor & 5 & 7 & 0.98 & 0.05 & 0.0324 & 0.003 & 0.02 & 0.02 \\
\hline 13 & Visiting Professor & 4 & 3 & 0.91 & 0.01 & 0 & 0.003 & 0.01 & 0.01 \\
\hline 14 & Associate Professor & 4 & 2 & 0.93 & 0.04 & 0.0043 & 0.035 & 0.14 & 0.07 \\
\hline 15 & Associate Professor & 4 & 8 & 1.11 & 0.02 & 0.0014 & 0 & 0 & 0 \\
\hline 16 & Full Professor & 4 & 6 & 1.25 & 0.04 & 0.0122 & 0.019 & 0.07 & 0.11 \\
\hline 17 & No UC3M & 4 & 1 & 0.94 & 0.01 & 0 & 0.017 & 0.07 & 0.02 \\
\hline 18 & Full Professor & 4 & 2 & 1.02 & 0.04 & 0.0010 & 0.167 & 0.83 & 0.33 \\
\hline & & & Highest & $2^{\text {nd }}$ highest & $3^{\text {rd }}$ highest & & & & \\
\hline
\end{tabular}

Table 6. Physics (more than 11 documents). 2000-2004.

\begin{tabular}{|c|c|c|c|c|c|c|c|c|c|}
\hline Rank & Position & Ndoc & Citations & NIF & Degree & Betweenness & Cluster Coef & Popularity & Prestige \\
\hline 1 & Full Professor & 36 & 40 & 1.17 & 0.08 & 0.02793 & 0.030 & 1.10 & 1.22 \\
\hline 2 & Associate Professor & 30 & 61 & 1.34 & 0.30 & 0.43322 & 0.608 & 18.25 & 37.12 \\
\hline 3 & PhD Assistant & 29 & 53 & 1.21 & 0.17 & 0.13694 & 0.069 & 2.15 & 3.68 \\
\hline 4 & Associate Professor & 26 & 79 & 1.25 & 0.25 & 0.27295 & 0.141 & 3.96 & 11.18 \\
\hline 5 & No UC3M & 25 & 34 & 1.18 & 0.06 & 0.01297 & 0.017 & 0.43 & 0.58 \\
\hline 6 & Associate Professor & 23 & 52 & 1.23 & 0.14 & 0.09649 & 0.049 & 1.17 & 2.54 \\
\hline 7 & Associate Professor & 22 & 46 & 1.30 & 0.11 & 0.14356 & 0.025 & 0.58 & 1.16 \\
\hline 8 & No UC3M & 19 & 56 & 1.42 & 0.12 & 0.02569 & 0.066 & 1.25 & 3.69 \\
\hline 9 & PhD Assistant & 18 & 51 & 1.34 & 0.15 & 0.07581 & 0.066 & 1.33 & 3.38 \\
\hline 10 & Associate Professor & 17 & 23 & 1.27 & 0.09 & 0.07878 & 0.037 & 0.67 & 0.86 \\
\hline 11 & Associate Professor & 15 & 18 & 1.20 & 0.07 & 0.02338 & 0.056 & 0.85 & 1.01 \\
\hline 12 & PhD Assistant & 15 & 34 & 1.32 & 0.05 & 0.01604 & 0.030 & 0.45 & 1.03 \\
\hline 13 & No UC3M & 15 & 39 & 1.27 & 0.03 & 0.00037 & 0.008 & 0.13 & 0.33 \\
\hline 14 & No UC3M & 14 & 39 & 1.28 & 0.02 & 0.00007 & 0.006 & 0.08 & 0.22 \\
\hline 15 & No UC3M & 13 & 39 & 1.28 & 0.02 & 0.00007 & 0.006 & 0.07 & 0.22 \\
\hline 16 & No UC3M & 12 & 33 & 1.29 & 0.02 & 0 & 0.004 & 0.05 & 0.13 \\
\hline 17 & Full Professor & 12 & 32 & 1.37 & 0.15 & 0.02869 & 0.142 & 1.70 & 4.53 \\
\hline & & & Highest & $2^{\text {nd }}$ highest & $3^{\text {rd }}$ highest & & & & \\
\hline
\end{tabular}

\section{Discussion}

An initial analysis of the behavior and evolution of the new indicators, popularity and prestige, yields suggestive results. By combining bibliometric and structural indicators, an author's rank in a list based on either measure can be qualified. It is interesting to note, for instance, that the actors ranking highest in terms of collaborative output, citations or clustering coefficient lack the characteristics necessary to be ranked equally highly in terms of popularity and prestige. 
The Spearman correlation values (Table 11) show the results of comparing three simple indicators (number of papers, number of citations and clustering coefficient) to the two hybrid indicators (popularity and prestige). The low correlation among variables confirms the lack of uniformity in authors' positions under the various indicators used. In other words, since an author's predominant position in terms of a simple indicator (production, visibility or collaboration) does not guarantee a comparable position in terms of popularity or prestige, these hybrid indicators, with respect to their predecessors, furnish novel and non-redundant information.

Table 7. Materials Science (more than 13 documents). 2000-2004.

\begin{tabular}{|c|c|c|c|c|c|c|c|c|c|}
\hline Rank & Position & Ndoc & Citations & NIF & Degree & Betweenness & Cluster Coef & Popularity & Prestige \\
\hline 1 & Full Professor & 65 & 43 & 1.03 & 0.34 & 0.323 & 0.41 & 28.14 & 17.80 \\
\hline 2 & Associate Professor & 50 & 27 & 1.04 & 0.23 & 0.071 & 0.26 & 13.29 & 7.04 \\
\hline 3 & Associate Professor & 26 & 90 & 1.19 & 0.19 & 0.150 & 0.16 & 4.25 & 14.71 \\
\hline 4 & Full Professor & 20 & 43 & 0.93 & 0.16 & 0.023 & 0.37 & 7.78 & 15.92 \\
\hline 5 & Associate Professor & 20 & 2 & 1.02 & 0.15 & 0.075 & 0.11 & 2.16 & 0.22 \\
\hline 6 & Associate Professor & 15 & 15 & 0.90 & 0.12 & 0.037 & 0.06 & 0.84 & 0.84 \\
\hline 7 & Associate Professor & 15 & 30 & 0.94 & 0.10 & 0.005 & 0.16 & 2.76 & 4.87 \\
\hline 8 & Full Professor & 15 & 78 & 1.38 & 0.10 & 0.002 & 0.16 & 2.35 & 12.24 \\
\hline 9 & Ayudante & 14 & 12 & 1.05 & 0.09 & 0.009 & 0.04 & 0.60 & 0.52 \\
\hline 10 & PhD Assistant & 14 & 2 & 1.09 & 0.08 & 0.009 & 0.03 & 0.43 & 0.06 \\
\hline & & & Highest & $2^{\text {nd }}$ highest & $3^{\text {rd }}$ highest & & & & \\
\hline
\end{tabular}

Table 8. Mathematics (more than 9 documents). 2000-2004.

\begin{tabular}{|c|c|c|c|c|c|c|c|c|c|}
\hline Rank & Position & Ndoc & Citations & NIF & Degree & Betweenness & Cluster Coef & Popularity & Prestige \\
\hline 1 & Full Professor & 41 & 36 & 0.86 & 0.17 & 0.08699 & 0.41 & 16.97 & 14.90 \\
\hline 2 & Associate Professor & 29 & 88 & 1.50 & 0.13 & 0.01957 & 0.61 & 17.63 & 53.49 \\
\hline 3 & Associate Professor & 25 & 58 & 1.31 & 0.09 & 0.06424 & 0.11 & 2.71 & 6.28 \\
\hline 4 & Associate Professor & 19 & 30 & 1.31 & 0.06 & 0.03302 & 0.09 & 1.65 & 2.61 \\
\hline 5 & Associate Professor & 12 & 37 & 1.50 & 0.07 & 0.02676 & 0.15 & 1.82 & 5.60 \\
\hline 6 & Full Professor & 12 & 7 & 0.92 & 0.08 & 0.03424 & 0.09 & 1.11 & 0.65 \\
\hline 7 & No UC3M & 10 & 12 & 1.00 & 0.01 & 0.00002 & 0.09 & 0.86 & 1.03 \\
\hline 8 & No UC3M & 10 & 12 & 1.02 & 0.01 & 0.00002 & 0.09 & 0.86 & 1.03 \\
\hline 9 & No UC3M & 10 & 40 & 1.31 & 0.03 & 0.00027 & 0.05 & 0.50 & 1.98 \\
\hline
\end{tabular}

Table 9. Communication Technologies (more than 7 documents). 2000-2004.

\begin{tabular}{|c|c|c|c|c|c|c|c|c|c|}
\hline Rank & Position & Ndoc & Citations & NIF & Degree & Betweenness & Cluster Coef & Popularity & Prestige \\
\hline 1 & Full Professor & 21 & 19 & 1.03 & 0.18 & 0.1535 & 0.26 & 5.36 & 4.85 \\
\hline 2 & Full Professor & 18 & 16 & 1.17 & 0.18 & 0.1554 & 0.23 & 4.06 & 3.61 \\
\hline 3 & Associate Professor & 13 & 17 & 1.10 & 0.12 & 0.0391 & 0.14 & 1.77 & 2.32 \\
\hline 4 & Associate Professor & 12 & 4 & 1.10 & 0.20 & 0.1135 & 0.56 & 6.73 & 2.24 \\
\hline 5 & Associate Professor & 10 & 16 & 1.13 & 0.10 & 0.0478 & 0.08 & 0.77 & 1.23 \\
\hline 6 & Part-time Professor & 8 & 7 & 1.21 & 0.15 & 0.0154 & 0.78 & 6.22 & 5.44 \\
\hline 7 & Associate Professor & 8 & 3 & 0.86 & 0.10 & 0.0054 & 0.31 & 2.51 & 0.94 \\
\hline 8 & Researcher & 8 & 3 & 0.83 & 0.10 & 0.0028 & 0.38 & 3.01 & 1.13 \\
\hline
\end{tabular}


Table 10. Electronic Technology (more than 5 documents). 2000-2004.

\begin{tabular}{|r|l|r|r|r|r|r|r|r|r|}
\hline Rank & \multicolumn{1}{|c|}{ Position } & Ndoc & Citations & \multicolumn{1}{c|}{ NIF } & \multicolumn{1}{c|}{ Degree } & Betweenness & Cluster Coef & Popularity & Prestige \\
\hline 1 & Associate Professor & 18 & 14 & 0.95 & 0.15 & 0.00650 & 0.25 & 4.42 & 3.44 \\
\hline 2 & Associate Professor & 18 & 14 & 0.93 & 0.17 & 0.01102 & 0.31 & 5.64 & 4.39 \\
\hline 3 & Full Professor & 15 & 9 & 1.33 & 0.12 & 0.06107 & 0.003 & 0.05 & 0.03 \\
\hline 4 & Associate Professor & 9 & 0 & 0.84 & 0.06 & 0.00157 & 0.09 & 0.81 & 0 \\
\hline 5 & No UC3M & 9 & 3 & 0.75 & 0.09 & 0.00226 & 0.07 & 0.61 & 0.20 \\
\hline 6 & Associate Professor & 9 & 3 & 0.87 & 0.09 & 0.00057 & 0.09 & 0.80 & 0.27 \\
\hline 7 & Associate Professor & 8 & 0 & 0.83 & 0.08 & 0.00636 & 0.15 & 1.16 & 0 \\
\hline 8 & No UC3M & 7 & 9 & 1.01 & 0.07 & 0.00028 & 0.05 & 0.33 & 0.42 \\
\hline 9 & Associate Professor & 7 & 4 & 1.53 & 0.05 & 0.00971 & 0.001 & 0.01 & 0.003 \\
\hline 10 & PhD Assistant & 7 & 0 & 0.87 & 0.13 & 0.00553 & 0.19 & 1.33 & 0 \\
\hline 11 & Associate Professor & 6 & 3 & 1.45 & 0.45 & 0.08932 & 0.99 & 5.94 & 2.97 \\
\hline
\end{tabular}

High correlation among authors' positions was observed in the Materials Science Department only, and was more significant between number of documents and popularity than between citations and prestige.

Moreover, the number of nodes in the co-authorship networks differed from one discipline to another, however, due to the variety and specialized nature of the research problems addressed and the number of years the network was in place. In addition, the mean number of co-authors per paper depended largely on whether the article was theoretical or experimental. Theory papers tended to have a smaller number of co-authors, while the number of collaborating researchers was larger in experimental science. Lastly, in co-authorship networks the clustering coefficient was sometimes affected by the existence in the network of subgroups of only a few authors who collaborated intensely and tended to form cliques or circles. Consequently, special network parameters may better characterize their degree of clustering.

Table 11. Spearman's rank correlation coefficient between simple and hybrid indicators.

\begin{tabular}{|l|r|r|r|r|r|r|r|r|r|}
\hline \multicolumn{1}{|c|}{ Indicators } & \multicolumn{1}{c|}{ COMP } & \multicolumn{1}{c|}{ ECO } & \multicolumn{1}{c|}{ BUSI } & \multicolumn{1}{c|}{ STAT } & \multicolumn{1}{c|}{ PHY } & \multicolumn{1}{c|}{ MATER } & \multicolumn{1}{c|}{ MATH } & COMM & \multicolumn{1}{c|}{ ELEC } \\
\hline ndoc-popularity & 0.348 & 0.428 & 0.574 & 0.059 & 0.253 & 0.812 & 0.676 & 0.665 & 0.256 \\
\hline ncit-prestige & 0.359 & 0.283 & 0.382 & 0.212 & 0.258 & 0.700 & 0.503 & 0.705 & 0.564 \\
\hline cc-popularity & 0.209 & 0.377 & 0.746 & 0.545 & 0.343 & 0.669 & 0.702 & 0.645 & 0.239 \\
\hline cc-prestige & ${ }^{\mathrm{a}} 0.086$ & 0.150 & 0.639 & ${ }^{\mathrm{g}} 0.010$ & 0.338 & 0.747 & 0.632 & 0.441 & ${ }^{\mathrm{m}}-0.004$ \\
\hline cc-ndoc & ${ }^{\mathrm{b}}-0.006$ & ${ }^{\mathrm{d}} 0.033$ & 0.356 & ${ }^{\mathrm{h}} 0.025$ & ${ }^{\mathrm{j}} 0.039$ & 0.673 & 0.547 & 0.283 & ${ }^{\mathrm{n}} 0.046$ \\
\hline cc-ncit & ${ }^{\mathrm{c}}-0.001$ & ${ }^{\mathrm{e}}-0.005$ & ${ }^{\mathrm{f}} 0.148$ & ${ }^{\mathrm{i}} 0.042$ & ${ }^{\mathrm{k}} 0.041$ & 0.396 & 0.402 & ${ }^{\mathrm{I}} 0.149$ & ${ }^{\circ} 0.031$ \\
\hline popularity-prestige & 0.626 & 0.860 & 0.915 & 0.234 & 0.984 & 0.576 & 0.769 & 0.805 & 0.748 \\
\hline
\end{tabular}

COMP: Computer Science, ECO: Economy, BUSI: Business Administration, STAT: Statistics, PHY: Physics, MATER: Materials Science, MATH: Mathematics, COMM: Communication Technologies, ELEC: Electronic Technology.

$\mathrm{p}=0.0$ except: $\mathrm{ap}=0.00004 ; \mathrm{bp}=0.94 ; \mathrm{cp}=0.35 ; \mathrm{dp}=0.01 ; \mathrm{ep}=0.63 ; \mathrm{fp}=0.001 ; \mathrm{gp}=0.12 ; \mathrm{hp}=0.04 ; \mathrm{ip}=$ $0.009 ; \mathrm{jp}=0.0001 ; \mathrm{kp}=0.0001 ; \mathrm{lp}=0.000002 ; \mathrm{mp}=0.49 ; \mathrm{np}=0.005 ; \mathrm{op}=0.02$.

In short, the new indicators emphasize not only the importance of the values furnished by traditional bibliometric indicators, but also the need for authors to have a prominent position from a structural standpoint. The Physics Department may be a good example of actors' behavior and show that a well-structured research environment may be much more beneficial than a larger number of co-authored papers or citations. Therefore, much has to be gained 
from the differentiation proposed, whereby authors are evaluated based not only on absolute volume but also their importance in the network. The latter is defined in terms of their ability to draw and shape working teams in which everyone collaborates with everyone else (distributed network), as opposed to groups in which the main node manages collaboration and keeps the various participating partners isolated (star network).

While the analysis was limited to the nine most productive departments in a specific institution, the results obtained are valid at the micro level addressed. Clustering coefficient values may vary depending on the size of the network, certainly. And the individual results for the professors analyzed may (and, when the time comes, should) be transferred to higher levels of aggregation (providing they are compatible), as suggested in the future lines of research discussed in the following section. But at the same time, the evaluation of all researchers in a common context, namely their department, affords sufficient guarantees for a valid comparison.

Nonetheless, certain reservations and exceptions must be borne in mind. The clustering coefficient values, like those of any other general or individual structural indicator, are impacted by the choice of the time period. A wide window for a given aggregate guarantees a larger number of papers and relationships, and vice versa. Moreover, the existence of different collaboration and citation cultures in different scientific fields, and even in different institutions, is an obstacle to inter-aggregate comparison.

\section{Conclusions}

The formulation of new convergence indicators has revealed the patterns of ties between actors as an invaluable aid to understanding networking on the individual scale. New formulas for characterizing researchers constitute valid and effective analysis and evaluation tools for identifying excellent authors, understood to be not only the most productive or visible, but also those able to combine those qualities with the effort involved in collective work. They are regarded to be excellent because their individual worth and capacity (number of articles published or citations) is enhanced by the merit deriving from joint work, with which they generate new, high quality scientific, technical and/or technological knowledge and guarantee the availability of new resources for further research.

This has made it possible to rank individual scientists and determine the differences revealed by indicators that distinguish among central professors, the most prestigious authors and the ones who act as intermediaries, reflecting the collaboration strategies deployed by the various actors to achieve recognition and impress their ideas on their colleagues.

Another interesting finding was that researchers' collaboration modus operandi is independent of their output or visibility.

These tools, then, are sensitive to traditional indicators, but also to the new demands of modern science as a self-organized system of interaction among individuals, furnishing information on researchers' environments and their behavior and attitudes within those environments (always collaborating with the same colleagues and keeping to the same lines of research, or changing scientific partners in pursuit of new challenges, for instance). In this new 
panorama, it does not suffice to "have" (published papers or citations): one must "be" from the perspective of the phrase so adeptly coined by Björneborn, connecto ergo sum (Björneborn, 2004).

As noted earlier, the scientific environment may influence individual behavior, particularly if such behavior affects research funding. Despite the exceptions described above that may put upward pressure on its value, the clustering coefficient is sufficiently robust to reduce the possible inflationary effects of adaptations in researcher behavior to accommodate new funding requirements. This is because the coefficient is based not only on the number of an actor's collaborative actions, but also on the degree of cohesion of the resulting relationships.

The new popularity and prestige indicators broaden the range of indicators used to quantify individual researcher development. Information can naturally be obtained on known indicators, and the differences between two authors with the same number of papers and citations can be readily quantified (using the $\mathrm{H}$-index). In much the same way, the combination of such indicators via the clustering coefficient can be used to distinguish between or qualify the positions of authors with the same number of papers or citations based on their collaboration practices.

The future enlargement of this type of analysis to broader domains or the comparison between micro-domains addressing similar subject matters will lead to an understanding of the relationships between UC3M author popularity and prestige on the international arena. The effect of endogamic sub-structures as well as and network size and density will also be ascertained and a more detailed and precise view of the evolution and scope of the results will be obtained. Nonetheless, the complexity of such studies conducted at the individual level in meso- or macro-aggregates should not be underestimated. The standardization of authors' names is the primary obstacle to analyzing such networks, for the number of authors may range from several thousand to several tens of thousands, depending on the domain and period analyzed.

\section{References}

Acedo, F. J., Barroso, C., Casanueva, C., et al. (2006). Co-authorship in Management and Organizational Studies: An empirical and network analysis. Journal of Management Studies, 43(5), 957-983.

Aksnes, D.W., \& Sivertsen, G. (2004). The effect of highly cited papers on national citation indicators. Scientometrics, 59(2), 213-224.

Barabási, A. L. (2002). Linked: The new science of networks. Cambridge: Perseus.

Barabási, A. L., Albert, R., \& Jeong, H. (1999). Mean-field theory for scale-free random networks. Physica A, 272, 173-187.

Batagelj, V., \& Mrvar, A. (2004). Pajek: Reference manual. Ljubljana: University.

Beaver, D., \& Rosen, R. (1978). Studies in scientific collaboration. Part I. The professional origins of scientific co-authorship. Scientometrics, 1, 65-84. 
Beaver, D., \& Rosen, R. (1979). Studies in scientific collaboration. Part II. Scientific coauthorship, research productivity and visibility in the French scientific elite. Scientometrics, 1(2), 133-149.

Bergstrom Laboratory. (2008). Eigenfactor [Online].Washington: University. <http://www.eigenfactor.org/methods.htm> [Consulted: 21-10-2008].

Björneborn, L. (2004). Small-world link structures across an academic web space: A library and information science approach. [Dissertation]. Copenhagen: Royal School of Library and Information Science.

Bollen, J., Rodríguez, M. A., \& van de Sompel, H. (2006). Journal status. Scientometrics, 69(3), 669-687.

Bonaccorsi, A., \& Daraio, C. (2003). Age effects in scientific productivity: The case of Italian National Research Council (CNR). Scientometrics, 58(1), 49-90.

Bordons, M., \& Zulueta, M. A. (1997). Comparison of research team activity in two biomedical fields. Scientometrics, 40(3), 423-436.

Bordons, M., Zulueta, M.A., Cabrero,A., \& Barrigón, S. (1995). Identifying research teams with bibliometric tools. In International Conference of the International Society for Scientometrics and Informetrics, 5॰ (pp. 83-91). Medford: Learned Information.

Börner, K., Dall'Asta, L., Ke,W., et al. (2005). Studying the emerging global brain: Analyzing and visualizing the impact of co-authorship teams. Complexity, 10(4), 57-67.

Braun, T., Brocken, M. G. M., Glänzel,W., et al. (1995). Hyphenation of databases in building scientometric indicators: Physics briefs-SCl based indicators of 13 European countries, 19801989. Scientometrics, 33(2), 131-148.

Calero, C., Buter, R., Cabello, C., et al. (2006). How to identify research groups using publication analysis: An example in the field of nanotechnology. Scientometrics, 66(2), 365-376.

Cohen, J. E. (1991). Size, age and productivity of scientific and technical research groups. Scientometrics, 20(3), 395-416.

Colman, A. M., Dhillon, D., \& Coulthard, B. (1995). A bibliometric evaluation of the research performance of British university politics departments: Publications in leading journals. Scientometrics, 32(1), 49-66.

Degenne, A., \& Forsé, M. (1999). Introducing social networks. London: Sage.

Gálvez, C., \& Moya-Anegón, F. (2006). The unification of institutional addresses applying parametrized finite-state graphs (P-FSG). Scientometrics, 69(2), 323-345.

Gálvez, C., \& Moya-Anegón, F. (2007a). Approximate personal name-matching through finitestate graphs. Journal of the American Society for Information Science and Technology, 58(13), 1960-1976. 
Gálvez, C., \& Moya-Anegón, F. (2007b). Standardizing formats of corporate source data. Scientometrics, 70(1), 3-26.

García-Aracil, A., Gutiérrez Gracia, A., \& Pérez-Martín, M. (2006). Analysis of the evaluation process of the research performance: An empirical case. Scientometrics, 67(2), 213-230.

Gauffriau, M., Larsen, P. O., Maye, I., et al. (2007). Publication, cooperation and productivity measures in scientific research. Scientometrics, 73(2), 175-214.

Genest, C., \& Thibault, C. (2001). Investigating the concentration within a research community using joint publications and co-authorship via intermediaries. Scientometrics, 51(2), 429-440.

Hanneman, R. A., \& Riddle, M. (2005). Introduction to social network methods [Online]. California: University of Riverside. <http://faculty.ucr.edu/ hanneman/nettext/> [Consulted: 31-3-2008].

Herrero, R. (2000). La terminología del análisis de redes. Problemas de definición y de traducción. Política y Sociedad, 33 (enero-marzo), 199-206.

Hirsch, J. E. (2005). An index to quantify an individual's scientific research output. Proceedings of the National Academy of Sciences of the United States of America, 102(46), 16569-16572.

Katz, J. S. (1992). Bibliometric assessment of intra national University-University collaboration. [Dissertation]. Brighton: University of Sussex.

Katz, J. S., \& Martin, B. R. (1997). What is research collaboration? Research Policy, 26, 1-18.

Kretschmer, H. (1997). Patterns of behaviour in coauthorship networks of invisible colleges. Scientometrics, 40(3), 579-591.

Laudel, G. (2002). What do we measure by co-authorship? Research Evaluation, 11(1), 3-15.

Lee, C. K. (2003). A scientometric study of the research performance of the Institute of Molecular and Cell Biology in Singapore. Scientometrics, 56(1), 95-110.

Leydesdorff, L., \& Vaughan, L. (2006). Co-occurrence matrices and their applications in Information science: Extending ACA to the Web environment. Journal of the American Society for Information Science and Technology, 57(12), 1616-1628.

Liu, X., Bollen, J., Nelson, M. L., et al. (2005). Co-authorship networks in the digital library research community. Information Processing and Management, 41, 1462-1480.

Mählck, P., \& Persson, O. (2000). Socio-bibliometric mapping of intra-departmental networks. Scientometrics, 49(1), 81-91.

Melin, G., \& Persson, O. (1996). Studying research collaboration using co-authorships. Scientometrics, 36(3), 363-377.

Miquel, J. F., Okubo, Y., Narváez, N., et al. (1989). Les scientifiques sont-ils ouverts à la coopération internationale? La Recherche, 20(206), 116-118. 
Moed, H. F., Luwel, M., Houben, J. A., et al. (1998). The effects of changes in the funding structure of the Flemish universities on their research capacity, productivity and impact during the 1980's and early 1990's. Scientometrics, 43(2), 231-255.

Molas-Gallart, J., \& Salter, A. (2002). Diversidad y excelencia: consideraciones sobre política científica. Sevilla: Institute for Prospective Technological Studies. (The IPTS Report, no. 66)

Molina, J. L., Muñoz, J., \& Losego, P. (2000). Red y realidad: aproximación al análisis de redes científicas. In Congreso Nacional de Psicología Social, VI. Oviedo: Universidad.

Molina, J. L., Muñoz, J. M., \& Domenech, M. (2002). Redes de publicaciones científicas: un análisis de la estructura de coautorías [Online]. 3. <http://revistaredes.rediris.es/htmlvol1/vol1 3.htm> [Consulted: 31-3-2008].

Mrvar, A. (2000). Network analysis using Pajek [Online]. Ljubljana: University. <http://mrvar.fdv.uni-lj.si/sola/info4> [Consulted: 31-3-2008].

Noyons, E. C. M., Moed, H. F., \& van Raan, A. F. J. (1999). Integrating research performance analysis and science mapping. Scientometrics, 46(3), 591-604.

Olmeda Gómez, C., Perianes-Rodríguez, A., \& Ovalle-Perandones, M. A. (2005). Medir y evaluar la excelencia de la investigación científica: retos y soluciones. In Encuentros Internacionales sobre Sistemas de Información y Documentación, X. Zaragoza: Universidad.

Otte, E., \& Rousseau, R. (2002). Social network analysis: A powerful strategy, also for the information sciences. Journal of Information Science, 28(6), 441-453.

Price, D. J. (1976). A general theory of bibliometric and other cumulative advantage processes. Journal of the American Society for Information Science, 27(5), 292-306.

Qurashi, M. M. (1993). Dependence of publication-rate on size of some university groups and departments in UK and Greece in comparison with NCI, USA. Scientometrics, 27(1), 19-38.

Rey-Rocha, J., Garzón-García, B., \& Martín-Sempere, M. J. (2006). Scientists' performance and consolidation of research teams in Biology and Biomedicine at the Spanish Council for Scientific Research. Scientometrics, 69(2), 183-212.

Rey-Rocha, J., Martín-Sempere, M. J., \& Garzón-García, B. (2002). Research productivity of scientists in consolidated vs. non-consolidated teams: The case of Spanish university geologists. Scientometrics, 55(1), 137-156.

Rogers, E. M., \& Kincaid, D. L. (1981). Communication networks: Toward a new paradigm for research. New York: Free Press.

SCImago Research Group. (2007). SClmago Journal and Country Rank [Online]. <http://www.scimagojr.com/SCImagoJournalRank.pdf> [Consulted: 21-10-2008].

Seglen, P. O., \& Aksnes, D. W. (2000). Scientific productivity and group size: A bibliometric analysis of Norwegian microbiological research. Scientometrics, 49(1), 125-143. 
Smith, D., \& Katz, J. S. (2000). Collaborative approaches to research. Brighton: Science Policy Research Unit.

Subramanyam, K. (1983). Bibliometric studies of research collaboration: A review. Journal of Information Science, 6(1), 33-38.

Thomson Reuters. (2008). The Thomson Scientific impact factor [Online]. Philadelphia: <http://www.thomsonreuters.com/businessunits/scientific/free/essays/impactfactor/> [Consulted: 21-10-2008].

Tijssen, R. J.W., Visser,M. S., \& van Leeuwen, T. N. (2002). Benchmarking international scientific excellence: Are highly cited research papers an appropriate frame of reference? Scientometrics, 54(3), 381-397.

van Leeuwen, T. N., \& Moed, H. F. (2005). Characteristics of journal impact factors: The effects of uncitedness and citation distribution on the understanding of journal impact factors. Scientometrics, 63(2), 357-371.

Vargas-Quesada, B., \& Moya-Anegón, F. (2007). Visualizing the structure of science. Berlin: Springer.

Vuckovic-Dekic, L. (2003). Authorship-coauthorship. Archive of Oncology, 11(3), 211-212.

Wagner, C. S., \& Leydesdorff, L. (2005). Network structure, self-organization and the growth of international collaboration in science. Research Policy, 34, 1608-1618.

Watts, D. J., \& Strogatz, S. H. (1998). Collective dynamics of small-world networks. Nature, 393, 440-442.

White, H. D. (2003). Author cocitation analysis and Pearson's r. Journal of the American Society for Information Science and Technology, 54 (13), 1250-1259.

Zulueta, M. A., \& Bordons, M. (1999). A global approach to the study of teams in multidisciplinary research areas through bibliometric indicators. Research Evaluation, 8(2), 111-118.

Zulueta, M. A., Cabrero, A., \& Bordons, M. (1999). Identificación y estudio de grupos de investigación a través de indicadores bibliométricos. Revista Española de Documentación Científica, 23(3), 333-347. 